\title{
OPTIMUM EVACUATION IN PUBLIC GATHERING PLACES DURING THE TIME OF DISASTER
}

\author{
Dilip Kumar P V, Sriram Kiran B, \\ Graduate Student \\ Computer Aided Structural Engineering \\ International Institute of Information Technology \\ Gachibowli, Hyderabad 500 032, INDIA \\ \{dilipkumar, sriram_bk\}@students.iiit.ac.in
}

\author{
Ramancharla Pradeep Kumar \\ Earthquake Engineering Research Centre \\ International Institute of Information Technology \\ Gachibowli, Hyderabad 500 032, INDIA \\ ramancharla@iiit.ac.in
}

\begin{abstract}
Urbanization is rapidly increasing all over the world. Past 2 decades in India, many cities have attracted large population. Reasons being the belief of better education, health care, job/business prospects, etc. For meeting the demands of population density, many high-rise structures and large public gathering places are emerging in cities. Places where few thousands of people can meet are quite common in major cities. It is due to this reason, evacuation at the public gathering places has gained a lot of importance.

Though some traditional hand calculation procedures are available for the estimation of evacuation time, we have attempted to simulate the same in more realistic and reliable way by using latest computational techniques. In this paper, we developed a procedure to calculate the optimum evacuation time by taking input parameters like dimensions of the building, number of doors, size of doors, number of people and seating arrangement. This tool will help architect in efficient design of a public gathering place.
\end{abstract}

\section{KEYWORDS}

Building Evacuation, Public Gathering Places, Disaster, Simulation and Optimum Time

\section{INTRODUCTION}

Urbanization in India is rapidly increasing, considering infrastructure wise big shopping complexes, theaters, auditoriums and many other building and facilities are getting bigger and bigger and attract more and more people. These crowds have to be routed through the building in an efficient manner especially at the disaster times.

These days optimum evacuation is being given more and more importance in light of recent disasters like fire accidents at public gathering places few examples are on $16^{\text {th }}$ July 2004 "83 children killed in school fire in Kumbakonam" [1], on $3^{\text {rd }}$ February 2004"Srirangam wedding tragedy, which cost 62 lives because of fire accident in the marriage hall",[2], on May 22, 2005 "Bomb explosions rocked two cinema halls in Delhi injuring at least 40 people ${ }^{\text {"[3] }}$.There are many instances in the history involving trampling and crushing occurred in crowded places due to emergency evacuation. Through the studies of evacuation we can hope to design smarter spaces and identify problem areas. At last it is all about to design safer and more efficient buildings, concert halls and other public gathering places.

Although the regulatory provisions governing egress design are prescribed, the actual performance of the evacuation systems is difficult to asses. There have been numerous incidents reported regarding over crowding and crushing during emergency situations occurring in sport stadiums, theaters, social gathering places and other facilities.

The shape of a particular building, parameters like size, number and location of doors has much to do with congestion and crowding. Studies are still going on to improve public safety in public 
gathering places involving many disciplines architectural design for safe evacuation, crowd planning and management, crowd simulation, emergency planning and many others.

Applying that knowledge in the design of buildings has the potential to lead to optimized designs in terms of the level of safety, architectural freedom and costs. Traditional building rules targeting safe evacuation are however in most cases based on a much simplified model of the evacuation process, which does not allow the use of the currently available knowledge and technology.

In this research, using the currently available knowledge and latest technology we have developed a tool to calculate the optimum evacuation time of a particular building plan changing factors like number of persons, parameters of the building like number, size, and location of doors, which can also simulate the movement of public during the evacuation at normal and emergency conditions.

\section{REVIEW OF EXISTING EVACUATION MODELS}

Before embarking on this discussion it is useful to review the past and current models, one of the essential concepts of safety in buildings is the rapid and adequate evacuation of all the occupants of the building in case of any accident. For example many of the safety measures introduced in the design and operation of the building are aimed at ensuring that the occupants can safely leave the building before they are over taken by heat and toxic products and before the building collapses, and for this many models have been developed to find the evacuation time of a particular building, congestion areas, bottle necks and other parameters adding for improper evacuation.

To achieve a more realistic evacuation calculation, engineers have been looking to evacuation computer models to assess a building's life safety. Currently, there are a number of evacuation models to choose from, each with unique characteristics and specialties.

Few of the models which are currently available to the public are FPETool ${ }^{[6]}$, EVACNET4 ${ }^{[7,8]}$,

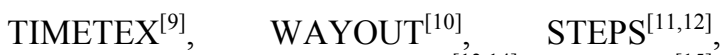
PEDROUTE / PAXPORT ${ }^{[13,14]}$, ASERI ${ }^{[15]}$, building EXODUS ${ }^{[16]}$, EXITT ${ }^{[17,18]}$, models available on consultancy basis are PathFinder ${ }^{[19]}$, EESCAPE $^{[20]}$ Myriad $^{[21,22]}$, there are other models which have not yet been released and others which are no longer in use.

And each model has at least one of these special features like Counterflow, Manual exit block/obstacles, Fire conditions affect behaviour, Defining groups , Disabilities/slow occupant groups, Delays/pre-movement times, Elevator use, Toxicity of the occupants, Impatience/drive variables, Route choice of the occupants/occupant distribution.

These models have been categorized using primary category labelled modelling method, it describes about the calculation of evacuation times for buildings like behavioural model incorporates decision making by occupants or actions that are performed due to conditions in the building. Movement modelling shows the occupants move from one point to another point, exit or place of safety, key in showing congestion areas, queuing or bottlenecks with in the simulated building. Partial behaviour models primarily calculate occupant movement, but begin to simulate behaviours. Possible behaviours could be implicitly represented by pre-movement time distributions among the occupants, unique occupant characteristics, overtaking behaviour, and the introduction of smoke or smoke effects to the occupant. These are models capable of simulating an entire building, and occupants' movements throughout the model are based on observed human behaviour data.

Purpose of the model as it pertains to certain building types, models that can simulate any type of building, models that specialize in residences, models that specialize in public transport stations, models that are capable of simulating low-rise buildings only and models that only simulate 1route/exit of the building.

A fine network model divides a floor plan into a number of small grid cells that the occupants move to and from. The coarse network models divide the floor plan into rooms, corridors, stair sections, etc. and the occupants move from one room to another. A continuous network model applies a 
2D (continuous) space to the floor plans of the structure, allowing the occupants to walk from one point in space to another throughout the building.

Perspective of the model explains how the model views the occupants and how the occupants view the building. Two ways that a model can view the occupants are globally and individually, they are differentiated by tracking movement of individual or a homogeneous group of people moving towards the exits. Individual perspective of the occupants is more detailed as we can know the position of each occupant throughout the simulation. The occupant can view the building in either a global or individual way. An occupant's individual view of the building is one where the occupant is not all knowing of the building's exit paths and decides his/her route based on information

Behaviour of the occupants is represented in many different ways like No behaviour denotes that only the movement aspect of the evacuation, Implicit behaviour represents those models that attempt to model behaviour implicitly by assigning certain response delays or occupant characteristics that affect movement throughout the evacuation, Conditional behaviour reflects models that assign individual actions to a person or group of occupants that are affected by structural or environmental conditions of the evacuation, Artificial Intelligence resembles the models that attempt to simulate human intelligence throughout the evacuation, Probabilistic represents that many of the rules or conditional-based models are stochastic, allowing for the variations in outcome by repeating certain simulations.

Movement one of the main factors refers to how the models move occupants throughout the building. In most of the models occupants are usually assigned a specific velocity by the user or modelling program. The differences in the models occur when the occupants become closer in a high density situation, resulting in queuing and congestion within the building. Few of them are Density correlation model assigns a speed and flow to individuals or populations based on the density of the space, User's choice where user assigns speed, flow, and density values to certain spaces of the building, Inter-person distance where each individual is surrounded by a 360 "bubble" that allows them only a certain minimum distance from other occupants, obstacles, and components of the building, Potential in which each grid cell in the space is given a certain number value, or potential, from a particular point in the building that will move occupants throughout the space in a certain direction. Occupants follow a potential map and attempt to lower their potential with every step or grid cell they travel to.

Visualization identifies whether the model allows the user to visualize the evacuation output from the structure. Visualizations of the evacuation allow the user to see where the bottlenecks and points of congestion are located inside the space. Many of the models allow for at least 2-D visualization (2D), and recently more have released versions or collaborate with other virtual programs that will present results in 3-D (3-D). Other models do not have any visualization capabilities.

As time passes, more evacuation models will be developed and many of the current models will be updated by developers.

\section{PROPOSED MODEL}

The model developed attempts to take into consideration of building parameters

1) Number of doors

2) Location of doors

3) Size of doors

4) Number of occupants in the building.

This model tracks the trajectory of each individual as they make their way out of the enclosure or are over come by accidents in the building.

This model is designed to calculate the optimum time of evacuation and also to simulate the evacuation of large numbers of people from a different variety of enclosures. This time is calculated by changing parameters of the building. The model developed using object oriented techniques is based on rules. The progressive motion of each individual is being determined by a set of rules.

The figure-1 shows the total working process of the proposed model. 


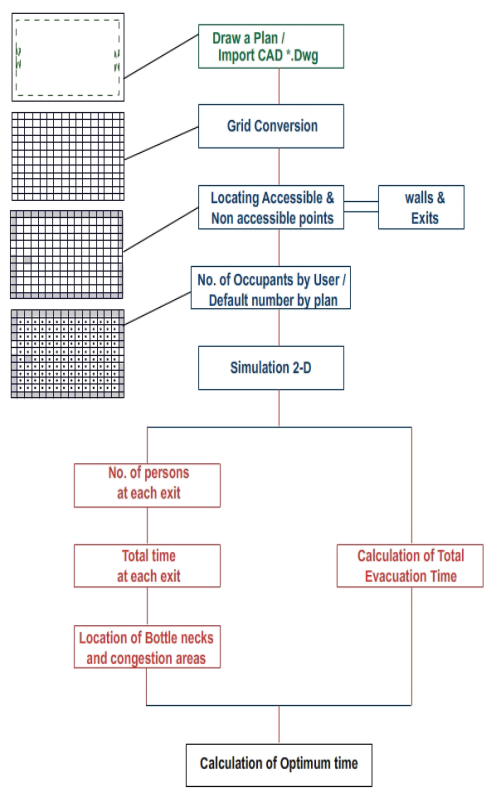

Figure 1 Work Flow Diagram

This model uses fine network which can effectively describe the movement pattern of each individual in a building. Such information can be adapted to a virtual reality presentation that can help building designers in presenting their design effectively. This can also model the relative coordinates of each individual at any point of time. It can effectively handle the individual and crowd behaviour.

The model developed uses the information from the user to draw the plan of a building in terms of walls, columns, other obstacles as inaccessible points and doors as accessible points. Now the total plan is divided in to small grid cells which can be occupied by a person. Number of occupants can be mentioned by the user in terms of percentage or else default number of occupants is taken according to the number of accessible grid cells.

Each occupant in the building is represented by an agent who has special properties:

1) Constant speed of $1.27 \mathrm{~m} / \mathrm{s}$,

2) Only one agent can occupy each grid cell at any point of time.

3) Takes individual decision.

4) Analyze the situation
5) The default grid cell size is $0.25 \mathrm{~m}$ by $0.25 \mathrm{~m}$ as the cell size can be changed by the user.

In high density situation or queuing, the movement speed is affected by the availability of the next grid cell, individual agent has eight possible decisions surrounding the grid cell as shown in the fig- 2 and the decision of where to go is based on which of the adjacent grid cell is nearer to the exit, in case of more than one grid cell availability, random function is used to choose the next grid cell.

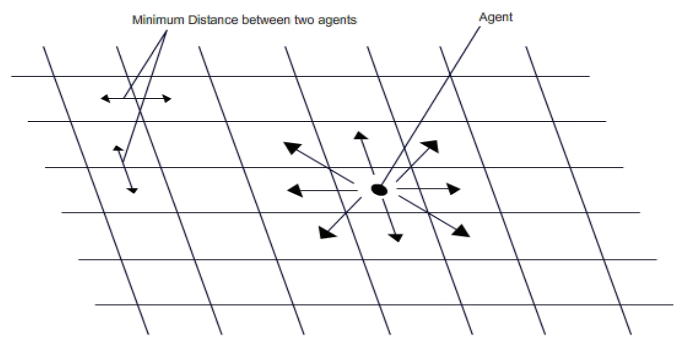

Figure 2 Computer Agent

A concept of multi-agent based computational system has been prototyped, which is able to demonstrate some emergent human social behaviors, such as competitive behavior, queuing behavior, herding behavior, and bi-directional crowd flow through simulating the behavior of human agents.

2-D Simulation is one of the important factors which show the actual movement of occupants during their evacuation and also shows the places of congestion bottlenecks throughout the building, which can be well designed.

The fig-3 shows the snapshot of the proposed model which has the input parameters dimensions of the plan, number of doors, location of doors and number of occupants. After the simulation is completed the data we have are number of persons at each door, total time taken at each door and total time of evacuation.

Now optimum time is calculated for the different combinations

1) Location of doors are changed

2) Number of doors are changed

3) Sizes of doors are changed

4) Number of occupants are changed 
For all the above combinations graphs are plotted against time and optimum time is calculated.

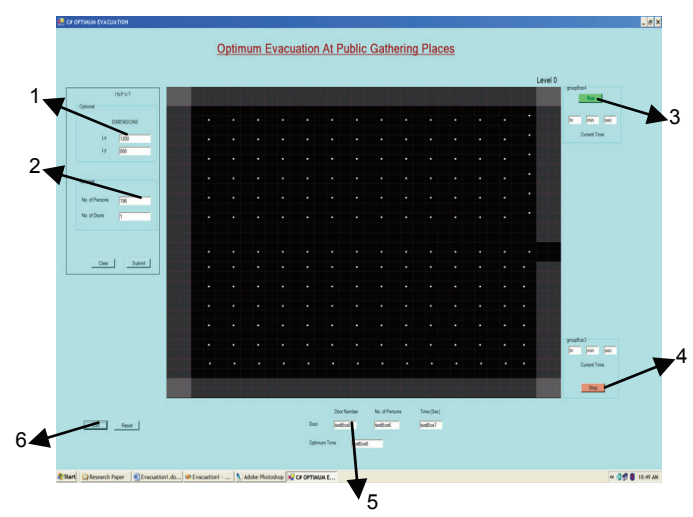

Figure 3 Proposed Model

\section{INPUT AND OUTPUT FROM MODEL}

1) Dimensions of the room (I)

2) Number of persons (I/U)

3) Timer start $(\mathrm{O})$

4) Timer stop $(\mathrm{O})$

5) Given door number (I) will get number of persons $(\mathrm{O})$, time for that particular door $(\mathrm{O})$

6) Exit and Reset (U) (I-input, O-output, U-user)

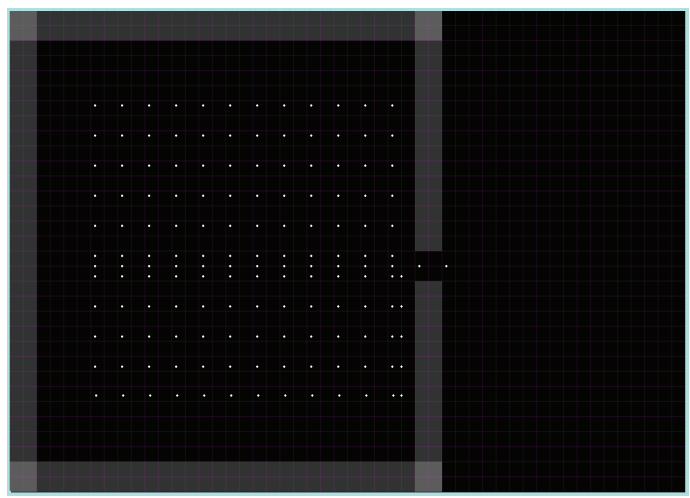

Figure 4 Proposed Model

Fig.4 shows the graphical area when the dimensions are changed. Figure also shows the movement of the agents to the door. The number of doors given during the compilation is one door. The numbers represented on the Fig. 3 from 1 to 6 gives the details of the proposed model Input, Output or User.

\section{RESULTS AND DISCUSSION}

The output file for proposed model is shown in the fig-5 and consists of model dimensions, agent speed, number of floors, door width, number of persons from each door and time duration.

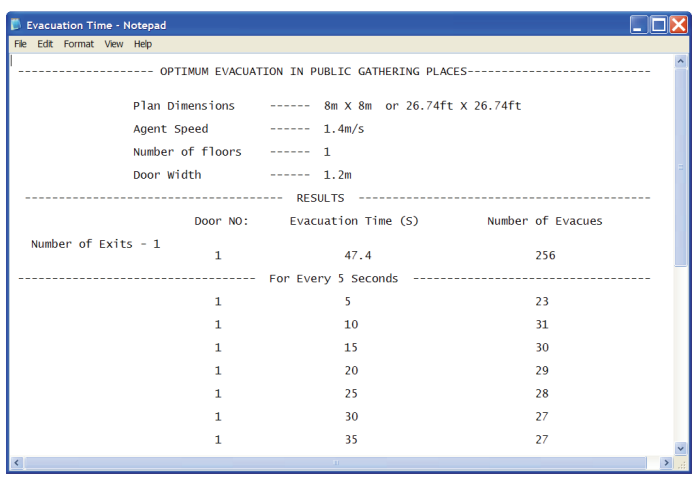

Figure 5 Output File

There are many situations where proper or improper planning can effect all of us in our day to day lives: complexes and residential buildings, outdoor arenas, and more.

Apart from calculating optimum evacuation time for the present existing plans, the model also calculates optimum evacuation time by slight variation in building parameters. As we can see from fig- 6 the parameters of the building are directly proportional to the time of evacuation and cost of project, this can be a secondary factor which can be considered for optimum cost of the project too.

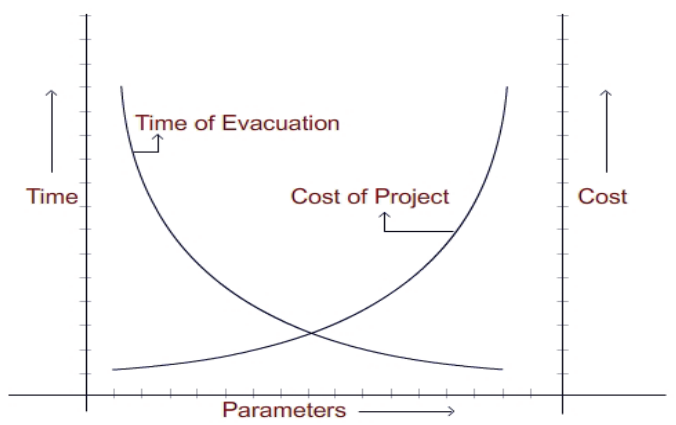

Figure 6 


\section{CONCLUSION}

The model presented, when properly applied and provided for can help with a greater understanding of occupant's movement at any public gathering places and indeed can help architects for better designs.

\section{REFERENCES}

[1] http://in.rediff.com/news/2004/jul/16tn.htm

[2] http://www.chennaionline.com/society/crim eandsociety/02fire.asp

[3] http://in.rediff.com/news/2005/may/22blast. htm

[4] Deal, S. (1995). Technical Reference Guide for FPETool Version 3.2 (Rep. No. NISTIR 5486-1) Natl. Inst. Stand. Technol.

[5] Francis, R. L. \& Saunders, P. B. (1979). EVACNET: Prototype Network Optimization Models for Building Evacuation (Rep. No. NBSIR 79-1593). Natl. Bur. Stand., (U.S.).

[6] Kisko, T. M., Francis, R. L., \& Nobel, C. R. (1998). EVACNET4 User's Guide, Version 10/29/98 University of Florida.

[7] Harrington, S. S. (1996). TIMTEX: A HydraluicFlow Model for Emergency Egress. MSci Department of Fire Protection Engineering, University of Maryland.

[8] Shestopal, V. O. \& Grubits, S. J. (1994). Evacuation Model for Merging Traffic flows in Multi-Room and Multi-Story Buildings. In Fire Safety ScienceProceedings of the $4^{\text {th }}$ International Symposium (pp. 625-632).

[9] Wall, J. M. \& Waterson, N. P. Predicting Evacuation Times -- A Comparison of the STEPS Simulation Approach with NFPA 130. Fire Command Studies, (in press).

[10] MacDonald, M. (2003).STEPS Simulation of Transient Evacuation and Pedestrian Movements User Manual. Unpublished Work 23

[11] Pedestrian Planning for the Olympic Park Railway Station, Sydney - Transport planning for the Olympic Games (2004). http://www.arup.com/insite/feature.cfm?f eatureid $=38$ [On-line].

[12] PAXPORT and PEDROUTE brochures (2004).http://www.halcrow.com [Online].

[13] ASERI (Advance Simulation of Evacuation of Real Individuals) A model to simulate evacuation and egress movement based on individual behavoural response (2004). http://www.ist-net.de [On-line].

[14] Gwynne, S., Galea, E. R., Lawrence, P., \& Filippidis, L. (1998). A Systematic Comparison of Model Predictions Produced by the buildingEXODUS Evacuation Model and the Tsukuba Pavilion Evacuation Data. Applied Fire Science, 7, 235-266.

[15] Levin, B. M. (1988). EXITT: A Simulation Model of Occupant Decisions and Actions in Residential Fires (Rep. No. NBSIR 88-3753). Natl. Inst. Stand. Technol.

[16] Levin, B. M. (1988). EXITT - A Simulation Model of Occupant Decisions and Actions in Residential Fires. In Fire Safety Science - Proceedings of the Second International Symposium (pp. 561-570).

[17] Cappuccio, J. (2000). Pathfinder: A Computer-Based Timed Egress Simulation. Fire Protection Engineering, 8, 11-12.

[18] Kendik, E. (1995). Methods of Design for Means of Egress: Towards a Quantitative Comparison of National Code Requirements. In Fire Safety Science -Proceedings of the 1st International Symposium (pp. 497-511).

[19] Still, G. K. (2004). VEgAS (Virtual Egress and Analysis System) available: http://www.crowddynamics.com

[20] Still, G. K. (2003). Internet Communication

[21] Erica D. Kuligowski, Richard D. Peacock (2005) A Review of Building Evacuation Models 